\title{
Impact of Climate Change on the Distribution of Tropical Parasitic and Other Infectious Diseases
}

\author{
${ }^{\mathrm{a}}$ Ahmad ${ }^{*}$, M. M., ${ }^{\mathrm{a}}$ Getso, B. U., ${ }^{\mathrm{b}}$ Ahmad, U. A. and ${ }^{\mathrm{c}}$ Abdullahi, I. I. \\ ${ }^{a}$ Department of Biology, Kano University of Science and Technology, Wudil \\ ${ }^{c}$ Department of Biology, Sa'adatuRimi College of Education, Kumbotso, kano. \\ ${ }^{d}$ Department of Biological Sciences, Jigawa State University, Kafin-Hausa
}

\begin{abstract}
Climate change is occurring as a result of warming of the earth's atmosphere due to human activity generating excess amounts of greenhouse gases. Because of its potential impact on the hydrologic cycle and severe weather events, climate change is expected to have an enormous effect on human health, including on the burden and distribution of many infectious diseases. Important environmental (climate) factors influencing the transmission cycles include temperature, precipitation and humidity, as well as the transmission components which include pathogen, vectors, non-biological and non-human reservoirs. The infectious diseases that will be most affected by climate change include those that are spread by insect vectors and by contaminated water. The burden of adverse health effects due to these infectious diseases will fall primarily on developing countries, while it is the developed countries that are primarily responsible for climate change.
\end{abstract}

Keywords: Climate change;Transmission; Tropical parasitic diseases; Infectious diseases; Vector- borne diseases; water-borne diseases

\section{Introduction}

The projected global increase in the distribution and prevalence of infectiousdiseases with climate change suggest a pending societal crisis. The subject is increasingly attracting the attention of health professionals and climate-change scientists, particularly with respect to malaria and other vector-transmitted human diseases(Kevin, 2009, Van Lieshout,et al., 2004, WHO, 1990 andPatz, et al., 2000). Assuming current trends continue, significant global warming via the "greenhouse effect" seems-inevitable; disequilibrium in physical and biological ecosystems will ensue, and the faster the changes occur the less likely it is that human (and other) societies will be able to adapt without serious resultant consequences.Natural climatic changes in the past have occurred over, thousands or millions of years; Global warming of 5000 to 15000 years ago completely changed the face of the planet; this was, however,insidious unlike the rapid change which man-made 'global-warming' will precipitate(Cook, 1992,Leaf, 1989, Schneider, 1990 and WHO, 2010). Present predictions on extent and geographical distribution of climatic change are based on incomplete scientific projections coupled with a significant quota of crystal-ball gazing. Disturbance of habitats due to alterations in land cover or climaticchange is considered to be the largest factor altering the risk ofinfectious diseases - for example, by affecting breeding sites ofdisease vectors or the biodiversity of vectors or reservoir hosts (Epstein et. al., 2003; Walsh et. al., 1993 andPascual, 2005).The potential impact of climatic change on communicable disease patterns can be summarized: (i) modification of vector (usually arthropod) ecology - this relates principally to infections currently prevalent in tropical and subtropical regions, (ii) intensification of human-related risk factors - including reduced availability and quality of drinking water, cooking and sanitation facilities, extent of irrigation, etc., and (iii) an increase in soil, airborne and other diseases, directly related to the socioeconomic consequences of changed in human behavior(Cook, 1992; Auld, 2004; Bradley, 1988).

There is no doubt that we are presently experiencing progressive global warming due to the increased production of 'greenhouse gases'. Global surface temperatures increased by approximately $0.3-0.6^{\circ} \mathrm{C}$ during the $20^{\text {th }}$ century (Intergovernmental Panel on Climate Change, 2001; Watson et al., 1995). There is evidence that this increase has anthropogenic causes (Barnett et al., 2001; Levituset al., 2001). Land and sea surface temperatures on the one hand and atmospheric pressure gradients on the other hand drive winds and weather. Global warming and the attending changes of weather patterns may have considerable impact on the hydrological cycle (heavy rainfalls, floods, megastorms, heat waves, droughts,freshwater shortages) and the vulnerable biosphere (deforestation, desertification, coral bleaching). Special attention focused on the effects on biodiversity, human health and the distribution of infectious diseases (Harvellet al., 1999, 2002; Intergovernmental Panel on Climate Change, 1995, 2001;). Amongst others, one threat is the increased exposure of man to vector- and water-borne diseases. As the global temperatures further increase, tropical insects may spread their habitats into more northern or southern latitudes and higher elevations followed by pathogen transmission. This intriguing idea was first suggested by Robert Shope (1991) and was taken further by several authors (Haines, 1991; Epsteinet al., 1993; Colwell, 1996; Patz,et al., 1996, 2005).However, there is still a 
debate whether the present emergence/reemergence (variation) of certain infectious diseases arose from climate change or from socioeconomic pressures (breakdown of public health infrastructure and insufficient diseaseprevention strategies in the respective areas) in combination with perturbations due to ecologic and demographic changes (Taubes, 1997; Gubler, 1998a; Reiter, 2001).

This review willattempt to summarized andhighlight the conclusion that extreme weather events have a significant impact on the transmissionof vector-borne and water-borne infectious diseases.

Broadly, infectious diseases may be classified into two categories based on themode of transmission: those spread directly from person to person (throughdirect contact or droplet exposure) and those spread indirectly through an interveningvector organism (mosquito or tick) or a non-biological physical vehicle(soil or water). Infectious diseases also may be classified by their natural reservoiras anthroponoses (human reservoir) or zoonoses (animal reservoir)Patz, et al., 20001.Many infectious diseases of humans are transmitted by insect vectors, thus typically cannot be transmitted directly from person to person, hence result in a wide range of clinical illness (Shuman, 2011). Many vector-borne diseases such as malaria (which is a vector-borne disease), are also considered to be water-borne since transmission is associated with factors such as rainfall. The global health impact of vector-borne diseases, particularly malaria and dengue fever, is tremendous with Current estimate of about 300-500 million people worldwide developing malaria annually, of whom one million die(Schneider, 1990 )Ninety percent of the deaths occur in Sub-Saharan Africa, and causes one out of every five childhood deaths in Africa. While malaria is an ancient human disease, dengue fever became widespread only in the middle of the last century(Hambrey, 1992).On the other hand around 50-100 million people are reported to be affected by dengue fever annually, with 500000 developing the most severe form of the disease- dengue hemorrhagic fever. There are 22000 deaths annually due to dengue fever, most of which occur in children. Many infectious diseases are transmitted by ingestion, inhalation, or contact with contaminated water (Gillett, 1981).

\section{General Impact of Climate Change on Infectious Diseases}

Before humans understood that microorganisms caused epidemic diseases, they knew that these diseases were intimately related to climate. For example, ancient Romans retreated to cooler hillside resorts in the summer to avoid malaria(WHO, 2010).For those infectious diseases transmitted by insect vectors, we know that vectors are more active at higher temperatures.10 Tropical species of mosquitoes such as Anopheles require temperatures above $16{ }^{\circ} \mathrm{C}$ to complete their life cycles, and malaria parasites are able to develop more rapidly within mosquitoes at higher temperatures $\left(>20^{\circ} \mathrm{C}\right)$. In the case of malaria due to Plasmodium falciparum, one mosquito can infect 200 individuals if temperature conditions are ideal, allowing for rapid spread of the disease. Vector-borne diseases such as malaria are also thought of as water-borne diseases, since mosquitoes typically thrive in aquatic habitats, where they lay their eggs in water-filled containers(Lafferty, 2009, Shuman, 2011). Thus, epidemics of malaria and dengue fever tend to occur annually during rainy seasons in the tropics and inter-annually after weather events. On the other hand, epidemics of the mosquito-borne West Nile virus infection can occur during times of drought. This happens because mosquitoes and birds - the primary hosts of the virus - are brought into close proximity at scarce water sources, enhancing transmission of the disease between mosquitoes and birds (and thus to humans). In addition, natural predators of mosquitoes are greatly reduced during times of drought as wetlands dry up(Shuman, 2011).

Like vector-borne diseases, water-borne diseases are also strongly impacted by climate, particularly the effect of climate on the hydrologic cycle. During times of drought, water scarcity results in poor sanitation and exposure of much of the population to potentially contaminated water. For example, an epidemic of cholera occurred in late 2009 in northern Kenya after a severe drought, with over 4700 cases reported in one month, including 119 deaths (Gettleman, 2009).Excess rainfall and flooding, like drought, can also contribute to epidemics of water-borne infectious diseases, in this case due to poor sanitation resulting from run-off from overwhelmed sewage lines or contamination of water by livestock. An example is the 1993 outbreak of diarrheal disease due to Cryptosporidium in Milwaukee, Wisconsin after heavy spring rains (Mackenzie, et. al., 1994).In this outbreak, there were over 403000 reported cases, demonstrating how widespread diarrheal disease can become when community water sources become contaminated.

\section{Disease classifications relevant to climate/health relationships}

Several different schemes allow specialists to classify infectious diseases. For clinicianswho are concerned with treatment of infected patients, the clinical manifestationof the disease is of primary importance. Alternatively, microbiologiststend to classify infectious diseases by defining the characteristics of the microorganisms, such as viral or bacterial. For epidemiologists the two characteristicsof foremost importance are the method of transmission of the pathogen and itsnatural reservoir, since they are concerned primarily with controlling the spreadof disease and preventing future outbreaks(Nelson, 2000).Climate variability's effect on infectious diseases is determined largely by theunique transmission cycle of each pathogen. Transmission cycles 
that require avector or non-human host are more susceptible to external environmental influencesthan those diseases which include only the pathogen and human. Importantenvironmental factors include temperature, precipitation and humidity. Several possible transmissioncomponents include pathogen (viral, bacterial, etc.), vector (mosquito, snail,etc.), non-biological physical vehicle (water, soil, etc.), non-human reservoir(mice, deer, etc.) and human host. Epidemiologists classify infectious diseasesbroadly as anthroponoses or zoonoses, depending on the natural reservoir of thepathogen; and direct or indirect, depending on the mode of transmission of thepathogen. The following is a description of each category of disease,discussed in order of probable increasing susceptibility to climatic factors.

\section{Anthroponoses}

\section{Directly transmitted diseases}

Directly transmitted anthroponoses include diseases in which the pathogen normallyis transmitted directly between two human hosts through physical contactor droplet exposure. The transmission cycle of these diseases comprises two elements:pathogen and human host. Generally, these diseases are least likely to beinfluenced by climatic factors since the agent spends little to no time outside thehuman host. These diseases are susceptible to changes in human behaviour, suchas crowding and inadequate sanitation that may result from altered land-usecaused by climatic changes. Examples of directly transmitted anthroponosesinclude measles, TB, and sexually transmitted infections such as HIV, herpes andsyphilis (Daszak, et al., 1999, 2000 and 2001; Wilson, 2001).

\section{Zoonoses}

Directly transmitted zoonosis, are similar to directly transmitted anthroponosesin that the pathogen is transmitted through physical contact or droplet exposurebetween reservoirs. However, these agents are spread naturally among animalreservoirs and the infections of humans are considered to be a result of an accidentalhuman encounter. The persistence of these pathogens in nature is largelydependent on the interaction of the animal reservoir and external environmentthis can impact the rate of transmission, host immunity, rate of reproduction, and species death, rendering these diseases more susceptible to effects of climate variability. Hantavirus is a directly transmitted zoonosis that is naturally maintainedin rodent reservoirs and can be transmitted to humans at times ofincreased local abundance of the reservoir. Rabies is another directly transmittedzoonosis that naturally infects small mammals, although with very littleopportunity for widespread transmission, being highly pathogenic to its vertebratehost (WHO, 2010). Several of today's anthropogenic diseases, e.g. TB and HIV, originallyemerged from animals.

\section{Indirectly transmitted diseases (anthroponoses\&zoonoses)}

Indirectly transmitted anthroponoses are a class of diseases defined bypathogen transmission between two human hosts by either a physical vehicle(e.g. soil) or a biological vector (e.g. tick). These diseases require three components for acomplete transmission cycle: the pathogen, the physical vehicle or biologicalvector, and the human host. Most vectors require a blood meal from the vertebratehost in order to sustain life and reproduce. Indirectly transmitted anthroponosesinclude malaria and dengue fever, whereby the respective malariaparasite and the dengue virus are transmitted between human hosts by mosquitovectors (vector-borne disease). Indirectly transmitted water-borneanthroponosesare susceptible to climatic factors because the pathogens exist in the externalenvironment during part of their life cycles (Daszak,et al., 2001). Flooding may result in the contaminationof water supplies or the reproduction rate of the pathogen may beinfluenced by ambient air temperatures. Cholera is an indirectly transmittedwater-borne anthroponose that is transmitted by a water vehicle: the bacteria(Vibrio cholerae) reside in marine ecosystems by attaching to zooplankton. Survivalof these small crustaceans in turn depends on the abundance of their foodsupply, phytoplankton. Phytoplankton populations tend to increase (bloom)when ocean temperatures are warm. As a result of these ecological relationships, cholera outbreaks occur when ocean surface temperatures rise.Indirectly transmitted zoonoses on the other hand are similar to indirectly transmitted anthroponosesexcept that the natural cycle of transmission occurs between nonhumanvertebrates: humans are infected due to accidental encounters with aninfected vehicle or vector. This class of disease involves four components in thetransmission cycle: the pathogen, biological vector or physical vehicle, animalreservoir, and human host. These diseases are highly susceptible to a combinationof ecological and climatic factors because of the numerous components inthe transmission cycle, and the interaction of each of these with the external environment.Complex cycles of disease transmission also exist for several diseases whichcannot be classified simply by method of transmission or natural reservoir. Sucha disease is Rift Valley fever where the virus is primarily a zoonotic disease, spreadamong vertebrate hosts by the mosquito species Aedes. Primarily under flood conditions, Culexmosquitoes may feed upon infected ungulate hosts. This vector isreferred to as a bridge species because it feeds on humans also, resulting in spreadof the virus outside its normal zoonotic cycle. 


\section{Climate sensitivities of infectious diseases}

Both the infectious agent (protozoa, bacteria, viruses, etc) and the associatedvector organism (mosquitoes, ticks, sandflies, etc.) are very small and devoid ofthermostatic mechanisms. Their temperature and fluid levels are therefore determineddirectly by the local climate. Hence, there is a limited range of climaticconditions - the climate envelope - within which each infective or vector speciescan survive and reproduce(WHO, 1990; 2010; Lipp, et al., 2002). It is particularly notable that the incubation time ofa vectorborne infective agent within its vector organism is typically very sensitiveto changes in temperature, usually displaying an exponential relationship.Other climatic sensitivities for the agent, vector and host include level of precipitation,sea level elevation, wind and duration of sunlight (Patz, et al., 2001; Shuman, 2011).

\section{Seasonality of infectious disease}

Disease pattern may result from increased likelihoodof transmission due to indirect social or behavioral adaptations to the coldweather such as crowding indoors. Another possibility is that it may be attributeddirectly to pathogen sensitivities to climatic factors such as humidity. Inaddition to influenza, several other infectious diseases exhibit cyclic seasonalpatterns, which may be explained by climate (Bouma, et al., 1996; 1997;Andrew, et al., 2000).

In diverse regions around the world, enteric diseases show evidence of significant seasonal fluctuations. In Scotland, campylobacter infections are characterizedby short peaks in the spring (Colwell, 1998). In Bangladesh, cholera outbreaks occurduring the monsoon season (Colwell, 1996). In Peru, cyclospora infections peak in thesummer and subside in the winter (Madico.et al., 1997). Similarly, some vector-borne diseases (e.g.malaria and dengue fever) also show significant seasonal patterns whereby transmissionis highest in the months of heavy rainfall and humidity. Epidemics ofother infections (e.g. meningococcal meningitis) tend to erupt during the hot anddry season and subside soon after the beginning of the rainy season in sub-Saharan Africa (Chua, et al., 2002; Moore, 1992).

Seasonal fluctuations of infectious disease occurrence imply an associationwith climatic factors. However, to prove a causal link to climate, non-climaticfactors must be considered. Furthermore, in order to assess long-term climateinfluences on disease trends, data must span numerous seasons and utilize properstatistics to account for seasonal fluctuations.

\section{Vector-borne diseases}

Climatic factors variation effects in the transmission of vector-borne diseases include:

- Survival and reproduction rate of the vector

- Time of year and level of vector activity, specifically the biting rate

- Rate of development and reproduction of the pathogen within the vector(Kovats, et al., 2001).

Vectors, pathogens, and hosts each survive and reproduce within certain optimalclimatic conditions and changes in these conditions can modify greatly theseproperties of disease transmission. The most influential climatic factors for vector-bornediseases include temperature and precipitation but sea level elevation,wind, and daylight duration are additional important considerations (Graczyk, et al., 2000).

\section{Temperature sensitivity}

Extreme temperatures often are lethal to the survival of disease-causingpathogens but incremental changes in temperature may exert varying effects. Where a vector lives in an environment where the mean temperature approachesthe limit of physiological tolerance for the pathogen, a small increase in temperaturemay be lethal to the pathogen. Alternatively, where a vector lives in anenvironment of low mean temperature, a small increase in temperature mayresult in increased development, incubation and replication of the pathogen(Lindsay and Birley, 1996,Bradley, 1993). Temperature may modify the growth of disease carrying vectors by alteringtheir biting rates, as well as affect vector population dynamics and alter the rateat which they come into contact with humans. Finally, a shift in temperatureregime can alter the length of the transmission season(Gubler, et al., 2001).Disease carrying vectors may adapt to changes in temperature by changinggeographical distribution. An emergence of malaria in the cooler climates of theAfrican highlands may be a result of the mosquito vector shifting habitats to copewith increased ambient air temperatures(Cox, et al., 1999). There isrecent evidence to suggest that the pitcher-plant mosquito (Wyeomiasmithii) canadapt genetically to survive the longer growing seasons associated with climatechange. Bradshaw and Holzapfel demonstrated this by documenting a change inthe photoperiodic response between two different time periods in two populationsof pitcher-plant mosquitoes. The change in response was correlated to amarked genetic shift within the mosquito species. A greater degree of micro evolutionary response was associated with mosquito populations inhabitinghigher latitudes; the hypothesis is that because these populations have greaterselection pressure they have also a greater ability to evolve genetically. Althoughthis study was limited to one specific species of mosquito, it suggests that othermosquitoes, perhaps disease carrying vectors, may undergo an 
analogous microevolutionwhich would allow adaptation to altered seasonal patterns associatedwith global climate change(Bradshaw andHolzapfel, 2001).

\section{Temperature effects on selected vectors and vector-borne pathogens}

Vector

- Survival can decrease or increase depending on species;

- Some vectors have higher survival at higher latitudes and altitudes with higher temperatures;

- Changes in the susceptibility of vectors to some pathogens e.g. higher temperatures reduce size

of some vectors but reduce activity of others;

- Changes in the rate of vector population growth;

- Changes in feeding rate and host contact (may alter survival rate);

- Changes in seasonality of populations.

Pathogen

- Decreased extrinsic incubation period of pathogen in vector at higher temperatures

- Changes in transmission season

- Changes in distribution

- decreased viral replication.

\section{Precipitation/Water sensitivity}

Increased variability in precipitation may increase the presence of disease vectorsby expanding the size of existent larval habitat and creating new breeding grounds. In addition, increased precipitation may support a growth in food supplies which in turn support a greater population of vertebrate reservoirs. Unseasonable heavy rainfalls may cause flooding and decrease vector populations by eliminating larval habitats and creating unsuitable environments for vertebrate reservoirs. Alternatively, flooding may force insect or rodent vectors to seek refuge in houses and increase the likelihood of vector-human contact. Epidemics of leptospirosis, a rodentborne disease, have been documented following severe flooding in Brazil (Ko, et al., 1999). In the wet tropics unseasonable drought can cause rivers to slow, creating more stagnant pools that are ideal vector breeding habitats.

\section{Effects of changes in precipitation on selected vectors and vector-borne pathogens}

Vector

- Increased rain may increase larval habitat and vector population size by creating new habitat

- Excess rain or snowpack can eliminate habitat by flooding, decreasing vector population

- Low rainfall can create habitat by causing rivers to dry into pools (dry season malaria)

- Decreased rain can increase container-breeding mosquitoes by forcing increased water storage

- Epic rainfall events can synchronize vector host-seeking and virus transmission

- increased humidity increases vector survival; decreased humidity decreases vector survival.

Pathogen

Few direct effects but some data on humidity effects on malarial parasite development in the anopheles mosquito host.

Vertebrate host

- Increased rain can increase vegetation, food availability, and population size

- Increased rain can cause flooding: decreases population size but increases human contact.

\section{Humidity sensitivity}

Humidity can greatly influence transmission of vector-borne diseases, particularlyfor insect vectors. Mosquitoes and ticks can desiccate easily and survival decreases under dry conditions. Saturation deficit (similar to relative humidity) has been found to be one of the most critical determinants in climate/disease models, for example, dengue fever(Focks, et al., 1995; Hales, et al., 2002) and Lyme disease models(Mount, et al., 1997).

\section{Sea level sensitivity}

The projected rise in sea level associated with climate change is likely to decreaseor eliminate breeding habitats for salt-marsh mosquitoes. Bird and mammalianhosts that occupy this ecological niche may be threatened by extinction, whichwould also aid the elimination of viruses endemic to this habitat (Reeves, 1994). Alternatively, inland intrusion of salt water may turn former fresh water habitats into salt-marsh areas which could support vector and host species displaced fromformer salt-marsh habitats (Reeves, 1994).Vector-borne pathogens spend part of their life-cycle in cold-blooded arthropods that are subject tomany environmental 
factors. Changes in weather and climate that can affect transmission of vector-bornediseases include temperature, rainfall, wind, extreme flooding or drought, and sea level rise.

\section{Water-borne diseases}

Human exposure to water-borne infections can occur as a result of contact withcontaminated drinking water, recreational water, coastal water, or food. Exposuremay be a consequence of human processes (improper disposal of sewage wastes) or weather events. Rainfall patterns can influence the transport and disseminationof infectious agents while temperature can affect their growth and survival (Hall and Fauci, 2009;Rose, 2001). Most observed associations between climate and water-borne diseases are based on indirect evidence of seasonal variations. However, several studies provide quantitative evidence of water-borne diseases' links to climatic factors such asprecipitation and ambient air temperature.

\section{Temperature sensitivity}

Increasing temperatures may lengthen the seasonality or alter the geographicaldistribution of waterborne diseases; in the marine environment, warm temperatures create favourable conditions for red tides (blooms of toxic algae) which can increase the incidence of shellfish poisoning (Epstein, 1993). Increasing sea surface temperatures can indirectly influence the viability of enteric pathogens such as Vibrio choleraeby increasing their reservoir's food supply (Colwell, 1996). Ambient air temperatures also have been linked to hospital admissions of Peruvian children with diarrhoeal disease (Checkly, et al., 2000).

\section{Precipitation sensitivity}

Heavy rains can contaminate watersheds by transporting human and animalfaecal products and other wastes. Evidence of water contaminationfollowing heavy rains has been documented for cryptosporidium, giardia, and E.coli (Atherholt, 1998; Parmenter, 1999). This type of event may be increased in conditions ofhigh soil saturation due to more efficient microbial transport (Rose, 2001). At the otherextreme, water shortages in developing countries have been associated withincreases in diarrhoeal disease outbreaks that are likely attributed to improperhygiene (WHO, 1999).

\section{Conclusion}

Changes in infectious disease transmission patterns are a likelymajor consequence of climatechange. We need to learn moreabout the underlying complexcausal relationships, and apply thisinformation to the prediction offuture impacts, using morecomplete, better validated,integrated, models. In summary, climate change is a very real phenomenon which has already impacted the global distribution of infectious diseases. If climate change continues unabated, it is likely that the range of deadly diseases such as malaria will expand or shift, resulting in sickness and death as populations without pre-existing immunity are increasingly affected. It is our responsibility to take action now to prevent this from occurring. We must reduce greenhouse gas emissions by developing an international treaty, enacting legislation locally, and acting responsibly as individual citizens of the world. Finally, we must continue to seek answers as to how climate change will affect our most vulnerable populations, and we must do what we can to protect them.

\section{References}

[1]. Atherholt, T.B. et al.(1998):Effects of rainfall on Giardia and Cryptosporidium. Journal of the American Water Works Association 90(9): 66-80 (1998).

[2]. Auld, H. MacIver, D. andKlaassen, J.(2004): Heavy rainfall and waterborne disease outbreaks: the Walkerton example. J Toxicol Environ Health,Part A 2004; 67: 1879-87.

[3]. Intergovernmental Panel on Climate change (2001): the scientific basis. Contribution ofworking group I to the third assessment report of theIntergovernmental Panel on Climate Change. Cambridge:Cambridge University Press, 2001.

[4]. Sutherst, R.W. (2004): Global change and human vulnerability to vector-borne diseases. Clin.Microbiol. Rev.2004; 17: 136-73.

[5]. Van Lieshout, M., Kovats, R.S., Livermore, M.T.J. and Martens, P.(2004): Climate change and malaria: analysis of the SRES climate and socio-economic scenarios. Glob Environ Change 2004; 14: 87-99.

[6]. Tanser F., Sharp, B.L. and Le Sueur, D. (2003): Potential effect of climate change on malaria transmission in Africa. Lancet 2003; 362: 1792-98.

[7]. Bouma M.J. and van der Kaay, H.J. (1996): The El Niño Southern Oscillation and the historic malaria epidemics on the Indian subcontinent and Sri Lanka: an early warning system for future epidemics? Trop Med Int Health 1996; 1: 86-96.

[8]. Focks, D.A. et al. (1995): A simulation model of the epidemiology of urban dengue fever: literature analysis, model development, preliminary validation, and samples of simulation results. American Journal of Tropical Medicine and Hygiene 53(5): 489-506 (1995).

[9]. Hall B.F. andFauci, A.S.(2009): Malaria control, elimination, and eradication: the role of the evolving biomedical research agenda. $\mathrm{J}$ Infect Dis 2009; 200:1639-43.

[10]. Lipp E.,Huq, A. and Colwell, R. (2002): Effects of global climate on infectious disease: the cholera model. Clin.Microbiol Rev.2002; 15: 757-70.

[11]. Shope, R.E. (1991): Global climate change and infectious diseases: Environmental Health Perspectives, 1991, 96: 171-174.

[12]. Shope, R.E. (1997): Emergence of arbovirus diseases following ecological modifications: epidemiological consequences. In: Factors in the emergence of Arbovirus diseases, Saluzzo JF, B. Dodet (ed.). Elsevier, Paris, pp.19-22. 
[13]. Cook G.C. (1991): The impact of global environmental change on human disease patterns.THS Health Summary 1991;8(no 3):7-8

[14]. Cook G.C. (1992):Effect of global warming on the distribution of parasitic and other infectious diseases: Journal of the Royal Society of Medicine, Volume 85,November 1992.

[15]. Curto de Casas S.I. andCarcavallo, R.U. (1995): Climate change and vector-borne diseases distribution. Social Science and Medicine, 1995, 40: 1437-1440.

[16]. Leaf, A. (1989): Potential health effects of global climatic and environmental changes. N Eng1 J Med 1989;321:1577-83

[17]. World Health Organization (1990): Potential health effects of climatic change. Geneva: WHO, $1990: 58$.

[18]. Gillett J.D. (1981): Increased atmospheric carbon dioxide and the spread of parasitic disease. In: Canning EU, ed. Parasitological topics: a presentation volume to P C CGarnham FRS, on the occasion of his 80th birthday. Lawrence, Kansas: Society of Protozoologists, 1981: 106-11.

[19]. Sadik N. (1990): The state of the world population 1990. New York: United Nations Population Fund, 1990.

[20]. Garham P.C. (1964): Factors influencing the development of protozoa in their arthropodan hosts. In: Taylor AER, ed. Host parasite relationships in invertebrate hosts. Oxford: Blackwell Scientific, 1964:33-50

[21]. Bruce-Chwatt L.J. and de Zulueta J. (1980):The rise and fall of malaria in Europe a historico-epidemiological study. New York: Oxford University Press, 1980:240

[22]. Roberts L. (1988): Is there life after climatic change? Science NY 1988;242:1010-12

[23]. Roberts, L., U.E.C. Confalonieri, and J.L. Aaron, (2001): Too Little, Too Much: How the Quantity of Water Affects Human Health. Chapter in, Aaron J.L. and Patz J.A. (eds), Ecosystem Change and Public Health: A Global Perspective.Johns Hopkins University Press, Baltimore.

[24]. Parmenter, R.R. et al. (1999): Incidence of plague associated with increased winter-spring precipitation in New Mexico. American Journal of Tropical Medicine and Hygiene. 61(5): 814-821 (1999).

[25]. Patz, J.A., T.K. Graczyk, N. Geller, and A.Y. Vittor (2000): Effects of environmental change on emerging parasitic diseases. Int J Parasitol, 30, 1395-1405.

[26]. Patz J.A.(2005): Climate change. In: Frumkin H, ed. Environmental Health. San Francisco: Josey-Bass, 2005: 238-68.

[27]. Patz, J.A. Githeko, A.K. McCarty, J.P. Hussein, S., Confalonieri, U. and de Wet, N.(2001):Chapter 16.Climate Change and Infectious Diseases. In: Climate change impacts on the United States: the potential consequences of climate variability and change foundation report, U.G.C.R.P. National Assessment Synthesis Team, Cambridge, UK, Cambridge University Press, 2001.

[28]. Lafferty K.D. (2009): The ecology of climate change and infectious diseases. Ecology 2009;90:888-900.

[29]. Lindsay, S.W. \&Birley, M.H. (1996): Climate change and malaria transmission. Annals ofTropical Medicine and Parasitology 90(6): 573-588 (1996).

[30]. Daszak, P. and A.A. Cunningham. (1999): Anthropogenic change, biodiversity loss and a new agenda for emerging diseases. Journal of Parasitology, Aug., 85(4), 742-746.

[31]. Daszak, P.A., Cunningham, and A.D. Hyatt, (2000): Emerging infectious diseases of wildlife-threats to biodiversity and human health. Science, 287(5452).

[32]. Daszak, P., A.A., Cunningham, and A.D. Hyatt. (2001): Anthropogenic environmental change and the emergence of infectious diseases in wildlife. ActaTropica, 78(2), 103-116.

[33]. Shuman, E.K. (2011):Global Climate Change and Infectious Diseases. International Journal of Environment and Medicine. Vol 2 Number 1; January, 2011.

[34]. Shiraki, Y.N. Shibata, Y. Doi, and Y. Arakawa, (2004): Escherichia coli producing CTX-M-2 beta-lactamase in cattle, Japan. Emerg Infect Dis 10, 69-75.

[35]. Schneider S.H. (1990): Global warming. Cambridge: The Lutterworth Press, 1990:343

[36]. Hales, S. de Wet, N.Maindonald, J. and Woodward, A.(2002): Potential effect of population and climate changes on global distribution of dengue fever: an empirical model. Lancet 2002; 360: 830-34.

[37]. Hambrey, M. (1992): Secrets of a tropical ice age. New Sci 1992;1 February:42-9

[38]. World Health Organization(2010): Climate change. 2010. Available from

[39]. www.who.int/topics/climate/en (Accessed October 11, 2010).

[40]. Gettleman, J. (2009): Cholera epidemic infects thousands in Kenya. New York Times [Internet]. December 5, 2009. Available from www.nytimes. com/2009/12/05/world/africa/05kenya.html (Accessed October 11, 2010).

[41]. Ko, A.I. et al. (1999): Urban epidemic of severe leptospirosis in Brazil. Salvador Leptospirosis Study Group. Lancet 354(9181): 820-825 (1999).

[42]. Kovats, R.S. et al.(2001): Early effects of climate change: do they include changes invector-borne disease? Philosophical Transactions of the Royal Society of London BBiological Sciences 356(1411): 1057-1068 (2001).

[43]. Mackenzie, W.R., Hoxie, N.J., Proctor,and M.E., et al.(1994): A massive outbreak in Milwaukee of Cryptosporidium infection transmitted through the public water supply. N Engl J Med 1994;

[44]. 331:161-7.

[45]. Madico, G. et al. (1997): Epidemiology and treatment of Cyclosporacayetanensis infectionin Peruvian children. Clinical Infectious Diseases 24(5): 977-981 (1997)

[46]. Moore, P.S.(1992): Meningococcal meningitis in sub-Saharan Africa: a model for theepidemic process. Clinical Infectious Diseases 14(2): 515-525 (1992).

[47]. Mount, G.A. et al. (1997):Simulation of management strategies for the blacklegged tick (Acari: Ixodidae) and the Lyme disease spirochete, Borreliaburgdorferi. Journal of Medical Entomology 34(6): 672-683 (1997).

[48]. Walsh, J.F., D.H. Molyneux, and M.H. Birley, (1993): Deforestation: effects on vector-borne disease. Parasitology 106 Suppl: S55-75.

[49]. Colwell R.R. (1996): Global climate and infectious disease: the cholera paradigm. Science 274:

[50]. 2025-31.

[51]. Colwell, R.R. andPatz, J.A.(1998):Climate, infectious disease and health. Washington, DC,USA, American Academy of Microbiology, 1998.

[52]. Nelson, K.E. (2000): Early history of infectious disease: epidemiology and control of infectious diseases. In: Infectious Disease Epidemiology, Nelson, K.E. et al. eds. Gaithersburg, MD, USA, Aspen Publishers Inc. pp. 3-16, 2000.

[53]. Epstein, P.R.(1993): Algal blooms in the spread and persistence of cholera. Biosystems. 31(2-3): 209-221 (1993).

[54]. Epstein, P.R., Chivian,E. and Frith,K.(2003): Emerging diseases threaten conservation. Environmental Health Perspectives, Volume 111, Number 10, August 2003: A506-A507. 
[55]. Andrew, K. Githeko, Steve W. Lindsay, Ulisses E. Confalonieri, and Jonathan A. Patz (2000):Climate change and vectorborne diseases:a regional analysis:Special Theme - Environment and Health. Bulletin of the World Health Organization, 2000,78 (9) 1 .

[56]. Checkley, W., Epstein, L.D., Gilman, R.H.et al., (2000): Effects of El Niño and ambient temperature on hospital admissions for diarrhoeal diseases in Peruvian children. Lancet 2000; 355: 442-50.

[57]. Chua, K.B., B.H. Chua, and C.W. Wang, (2002): Anthropogenic deforestation,El Nino and the emergence of Nipah virus in Malaysia. Malaysian J. Pathol.24, 15-21.

[58]. Graczyk, T.K., B.M. Evans, C.J. Shiff, H.J. Karreman, and J.A. Patz,(2000): Environmental and geographical factors contributing to watershed contamination with cryptosporidium parvumoocysts. Environ. Res., Mar., 82(3), $263-271$.

[59]. Gubler, D.J., Reiter, P., Ebi, K.L., Yap, W., Nasci, R. andPatz, J.A.(2001). Climatevariability and change in the United States: Potential impacts onvector- and rodent-borne diseases. Environ Health Perspect2001;109 (suppl 2): $223-33$.

[60]. Bradley, D. and R. Narayan, (1988): Epidemiological patterns associated with agricultural activities in the tropics with special reference to vector-bornediseases. Effects of Agricultural Development on Vector-Borne Diseases.FAO Publication, No. AGL/MISC/12/87, pp.35-43.

[61]. Bradley, D.J.(1993).Human tropical diseases in a changing environment. Ciba FoundationSymposium, 175: 146-62; discussion 162-170 (1993).

[62]. Bradshaw, W.E. andHolzapfel, C.M.(2001): Genetic shift in photoperiodic response correlatedwith global warming. Proceedings of the National Academy of Sciences USA98(25): 14509-14511 (2001).

[63]. Cox, J. et al.,(199):Mapping malaria risk in the highlands of Africa. MARA/HIMAL technicalreport.Pp. 96, 1999.

[64]. Thomson, M.C. and S.J. Connor, (2000): Environmental information systems for the control of arthropod vectors of disease. Medical and Veterinary Entomology, 14, 227-244.

[65]. Service, M.W., (1984): Problems of vector-borne diseases and irrigation projects. Insect Science and its Application, 5, 227-231.

[66]. Pachauri R.K., Reisinger, A., eds. Climate change 2007; synthesis report-contribution of Working Groups I, II, and III to the Fourth Assessment Report of the Intergovernmental Panel on Climate Change. Geneva: IPCC, 2007.

[67]. Pascual, M. and Dobson, A. (2005): Seasonal patterns of infectious diseases. PLoS Med 2005; 2: e5.

[68]. Reeves, W.C. (1994).Potential effect of global warming on mosquito borne arboviruses. Journal of Medical Entomology, 1994,31: 323-332.

[69]. Rose, J.B., Epstein, P.R., Lipp, E.K., Sherman, B.H., Bernard, S.M. andPatz, J.A. (2001): Climate variability and change in the United States: potential impacts on water and foodborne diseases caused by microbiologic agents. Environ Health Perspect2001; 109 (suppl 2): 211-21.

[70]. Watson RT et al., eds. Climate change 1995; impacts,adaptations and mitigation of climate change: scientific-technicalanalysis; Contribution of Working Group II to the SecondAssessment Report of the Intergovernmental Panel on Climate.

[71]. Wilson, M.L.(2001): Ecology and infectious disease. In: Ecosystem change and public health: a global perspective, Aron J.L. \&Patz, J.A. eds. Baltimore, USA, John Hopkins University Press, pp. 283-324, 2001.

[72]. Monograph on water resources and human health in Europe. Rome, Italy, WHO European Centre for Environment and Health/European Environment Agency, 1999. 